\title{
PENGERUH JUMLAH ANGGOTA, TOTAL ASET, MODAL SENDIRI, DAN MODAL PINJAMAN TERHADAP SISA HASIL USAHA PADA KOPERASI SIMPAN PINJAM DI KOTA BOGOR
}

\section{THE EFFECT OF TOTAL MEMBERS, TOTAL ASSETS, EQUITY, AND LOAN CAPITAL ON NET PROFIT MARGIN IN SAVE LOANS COOPERATION IN THE CITY OF BOGOR}

\author{
Kartini T 1a \\ 1Program Studi manajemen, Fakultas Ekonomi, Universitas Djuanda. \\ a Korespondensi:Tini Kartini, E-mail: tini.kartini@unida.ac.id \\ (Diterima: 28-05-2019; Ditelaah: 29-05-2019; Disetujui: 12-07-2019)
}

\begin{abstract}
The successful development of a Savings and Loan Cooperative (KSP) is generally supported by management activities involving members, management and supervisors. This is what can spur growth in the number of members, total assets, own capital, and loan capital. These developments and growth are expected to be in line with the improvement in the cooperative's performance, which can be seen in the growth of profitability so that it will influence the Remaining Operations (SHU) policy. This study aims 1) to analyze the development of the number of members, total assets, own capital, and loan capital, as well as SHU policy on KSP in Bogor City; 2) to test the effect of the number of members, total assets, own capital, and loan capital on SHU policy simultaneously on KSP in Bogor City; 3) to examine the effect of the number of members, total assets, own capital, and loan capital on SHU policy partially on KSP in Bogor City; 4) to design KSP strategies and policies in Bogor City. The research method used is quantitative and qualitative research with descriptive and verification method approaches. The population is 21 KSP units. Meanwhile, the sampling technique uses purposive sampling where the sample is taken with certain criteria. KSP that met the criteria were obtained as many as 6 KSP units. The analysis technique uses multiple linear regression and is supported by qualitative information through interviews with in depth interview techniques. Based on the results of the study showed that simultaneous hypothesis testing using the F test and partially using a t test with a probability level of 5 percent $(0.05)$. The results of the $F$ test study explained that the number of members, total assets, own capital, and loan capital together had a positive and significant effect on SHU on KSP in Bogor City. T test results show that the number of members, total assets, and own capital have a positive and significant effect on SHU. Conversely, loan capital does not have a positive and significant effect on SHU on KSP in Bogor City.
\end{abstract}

Keywords: Equity, number of members, total assets, loan capital, net profit margin

\begin{abstract}
ABSTRAK
Keberhasilan perkembangan Koperasi Simpan Pinjam (KSP) secara umum didukung oleh aktivitas pengelolaan yang melibatkan anggota, pengurus, dan pengawas. Hal inilah yang dapat memacu pertumbuhan jumlah anggota, total aset, modal sendiri, dan modal pinjaman. Perkembangan dan pertumbuhan tersebut, diharapkan searah dengan membaiknya kinerja koperasi yang nampak pada pertumbuhan profitabilitas sehingga ikut mempengaruhi kebijakan Sisa Hasil Usaha (SHU). Penelitian ini bertujuan 1) untuk menganalisis perkembangan jumlah anggota, total aset, modal sendiri, dan modal pinjaman, serta
\end{abstract}


kebijakan SHU pada KSP di Kota Bogor; 2) untuk menguji pengaruh jumlah anggota, total aset, modal sendiri, dan modal pinjaman terhadap kebijakan SHU secara simultan pada KSP di Kota Bogor; 3) untuk menguji pengaruh jumlah anggota, total aset, modal sendiri, dan modal pinjaman terhadap kebijakan SHU secara parsial pada KSP di Kota Bogor; 4) untuk mendesain strategi dan kebijakan KSP di Kota Bogor. Metode penelitian yang digunakan adalah penelitian kuantitatif dan kualittaif dengan pendekatan metode deskriptif dan verifikatif. Populasi sebanyak 21 unit KSP. Sedangkan, teknik pengambilan sampel menggunakan purposive sampling di mana sampel diambil dengan kriteria tertentu. KSP yang memenuhi kriteria diperoleh sebanyak 6 unit KSP. Teknik analisis menggunakan regresi linier berganda dan didukung informasi kualitatif melalui wawancara dengan teknik in depth interview. Berdasarkan hasil penelitian menunjukkan bahwa pengujian hipotesis secara simultan dengan menggunakan uji $\mathrm{F}$ dan secara parsial menggunakan uji $\mathrm{t}$ dengan tingkat probabilitas sebesar 5 persen $(0,05)$. Hasil penelitian uji $\mathrm{F}$ menerangkan bahwa jumlah anggota, total aset, modal sendiri, dan modal pinjaman secara bersama-sama berpengaruh positif dan signifikan terhadap SHU pada KSP di Kota Bogor. Hasil uji t menunjukkan bahwa jumlah anggota, total aset, dan modal sendiri berpengaruh positif dan signifikan terhadap SHU. Sebaliknya, modal pinjaman tidak berpengaruh positif dan signifikan terhadap SHU pada KSP di Kota Bogor.

Kata kunci: jumlah anggota, modal sendiri, modal pijaman, total aset, sisa hasil usaha.

Kartini, T., (2020). Pengaruh jumlah anggota total aset, modal sendiri, dan modal pijaman terhadap SHU pada koperasi simpan pinjam di Kota Bogor. Jurnal Sosial Humaniora, 11(1), 75-86.

\section{PENDAHULUAN}

Model bisnis koperasi merupakan manifestasi konstitusi, yakni UUD 1945 Pasal 33 ayat 1 yang dinyatakan sebagai badan usaha yang sesuai untuk mewujudkan demokrasi dan mencerminkan sistem perekonomian yang disusun berdasarkan asas kekeluargaan.

Komitmen untuk menumbuhkan perekonomian nasional di Indonesia dengan berbasis koperasi tersebut terus dilakukan tidak hanya di berbagai kota-kota besar, namun dilakukan juga di berbagai kota, termasuk di Kota Bogor.

Koperasi Simpan Pinjam (KSP) merupakan salah satu jenis dari lembaga keuangan non bank yang menjadi fokus pembahasan dalam penelitian perkembangan lembaga keuangan di Asia Tenggara (Meagher, et., al., 2006).
Penilaian koperasi simpan pinjam dapat dianalisa melalui laporan keuangan dengan tujuan untuk mengkalkulasi Sisa Hasil Usaha (SHU), mengawasi aset milik koperasi untuk menghindari penyalahgunaan, dan sebagai dasar pengambilan keputusan. Salah satu indikator yang digunakan untuk mengukur kinerja koperasi adalah perkembangan SHU (Tambunan, 2009).

Dalam kurun waktu 5 (lima) tahun terakhir, sebanyak 6 unit KSP yang aktif dan dinilai representatif di Kota Bogor menunjukkan bahwa adanya peningkatan posisi jumlah anggota, total aset, modal sendiri, dan modal pinjaman, serta SHU. Adapun data jumlah anggota, total aset, modal sendiri, dan modal pinjaman pada KSP di Kota Bogor periode tahun 2013-2017 dapat dilihat pada tabel berikut ini: 
Tabel 1. Nilai Rata- rata Jumlah Anggota, Total Aset, Modal Sendiri, Modal Pinjaman dan SHU KSP dan KSPPS tahun 2013-2017

\begin{tabular}{cccccc}
\hline \multicolumn{7}{c}{ Perkembangan (\%) } \\
\hline Tahun & $\begin{array}{c}\text { Jumlah } \\
\text { Anggota }\end{array}$ & $\begin{array}{c}\text { Total } \\
\text { Aset }\end{array}$ & $\begin{array}{c}\text { Modal } \\
\text { Sendiri }\end{array}$ & $\begin{array}{c}\text { Modal } \\
\text { Pinjaman }\end{array}$ & SHU \\
\hline 2013 & - & - & - & & - \\
2014 & 5,79 & 6,83 & $(27,02)$ & $(22,67)$ & 13,90 \\
2015 & 2,50 & 4,87 & 7,09 & 0,67 & 4,41 \\
2016 & 18,33 & $(0,04)$ & 16,33 & 56,02 & $(9,68)$ \\
2017 & 2,61 & 0,21 & 7,70 & $(0,12)$ & $(2,49)$ \\
\hline Jumlah & $\mathbf{2 6 , 6 2}$ & $\mathbf{1 1 , 6 5}$ & $\mathbf{4 , 1 0}$ & $\mathbf{3 4 , 0 2}$ & $\mathbf{8 , 6 3}$ \\
\hline Rata-Rata & $\mathbf{7 , 3 1}$ & $\mathbf{2 , 9 7}$ & $\mathbf{0 , 8 2}$ & $\mathbf{8 , 4 8}$ & $\mathbf{1 , 5 4}$ \\
\hline
\end{tabular}

Sumber: Data Sekunder diolah, 2020.

Hasil dari Tabel 1, menunjukkan bahwa pada tahun 2014 rata-rata nilai modal sendiri dan modal pinjaman mengalami penurunan sebesar $27,02 \%$ dan $22,67 \%$. Namun demikian, rata-rata jumlah anggota dan total aset meningkat sebesar $5,79 \%$ dan 6,83\%. Nilai rata-rata SHU juga meningkat sebesar 13,90\%. Sebaliknya, pada tahun 2015 rata-rata nilai jumlah anggota, total aset, modal pinjaman, dan SHU mengalami peningkatan sebesar 2,5\%, 0,67\%, 4,87\%, dan 13,9\%. Kemudian, pada tahun 2016 terjadi peningkatan rata-rata nilai jumlah anggota, modal sendiri, dan modal pinjaman sebesar $18,33 \%, 7,09 \%$, dan $56,02 \%$, namun rata-rata total aset dan SHU menurun sebesar 0,04\% dan 9,68\%.

Kondisi yang tidak searah ini, menunjukkan bahwa jumlah anggota yang meningkat belum tentu menyebabkan total aset, modal sendiri, dan modal pinjaman meningkat pula, serta belum tentu memberikan dampak yang baik pula terhadap SHU.

\section{MATERI DAN METODE}

\section{Anggota}

Menurut UU No. 25 Tahun 1992 anggota koperasi adalah pemilik sekaligus pengguna jasa koperasi. Anggota koperasi ialah setiap warga negara Indonesia yang mampu melakukan tindakan hukum atau koperasi yang memenuhi persyaratan sebagaimana ditetapkan dalam anggaran dasar koperasi.

\section{Aset}

Sesuai dengan Standar Akuntansi Keuangan ETAP (2009), aset adalah sumber daya yang dikuasai entitas sebagai akibat dari peristiwa masa lalu dan dari mana manfaat ekonomi di masa depan diharapkan akan diperoleh entitas. Aset dimasukkan dalam neraca dengan saldo normal debit. Aset dikelompokkan menjadi aset lancer dan aset tetap.

\section{Modal Sendiri}

Menurut Riyanto (2001:21) modal sendiri adalah modal yang berasal dari perusahaan itu sendiri (cadangan, laba) atau berasal dari pengambil bagian, peserta atau pemilik (modal saham, modal peserta, dll). Menurut UU No. 25 Tahun 1992 modal sendiri merupakan modal yang menanggung risiko (equity) yang berasal dari siimpanan pokok, simpanan wajib, dana cadangan, dan hibah.

\section{Modal pinjaman}

Menurut Keown (2004:37), modal pinjaman/luar adalah pembiayaan yang diberikan oleh kreditur kepada perusahaan. Menurut Undang-undang No. 25 Tahun 1992 modal pinjaman koperasi dapat berasal dari anggota, koperasi lain dan atau anggotanya, bank dan lembaga keuangan lainnya, penerbitan obligasi dan surat utang lainnya, sumber lain yang sah.

\section{Sisa Hasil Usaha (SHU)}

Menurut Rudianto (2010:7) SHU adalah selisih antara penghasilan yang 
diterima selama periode tertentu dan pengorbanan yang dikeluarkan untuk memperoleh penghasilan itu.

Menurut UU No. 25 pasal 45 Tahun 1992 Sisa Hasil Usaha (SHU) koperasi merupakan pendapatan koperasi yang diperoleh dalam satu tahun buku dikurangi dengan biaya penyusutan, dan kewajiban lainnya termasuk pajak dalam tahun buku yang bersangkutan.

\section{Kerangka Pemikiran}

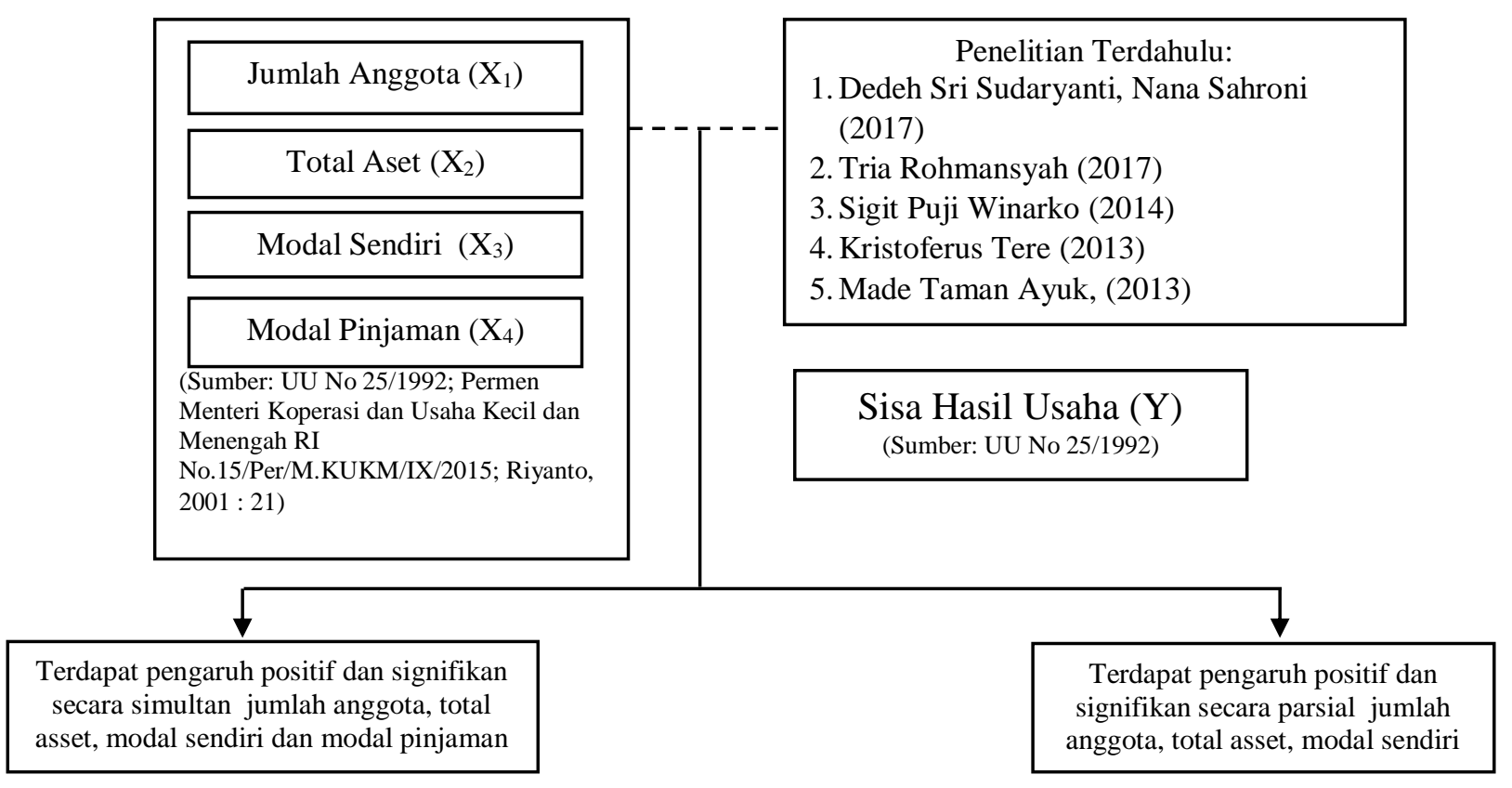

Gambar 1. Kerangka Pemikiran

\section{Desain Penelitian}

Pendekatan yang digunakan dalam penelitian ini adalah pendekatan kuantitatif dan kualitatif. Penelitian kuantitatif dapat diartikan sebagai metode penelitian digunakan untuk meneliti pada populasi atau sampel tertentu, dengan analisis data bersifat kuantitatif/statistik, tujuannya untuk menguji hipotesis yang telah ditetapkan. Sedangkan penelitian kualitatif didukung oleh informasi yang berdasarkan wawancara mendalam (in depth interview).

Desain penelitian yang digunakan dalam penelitian ini adalah metode deskriptif dan verifikatif. Metode deskriptif merupakan metode yang berkaitan dengan pertanyaan terhadap keberadaan variabel mandiri, baik hanya pada satu variabel atau lebih. Sedangkan pengertian verifikatif adalah penelitian yang dilakukan terhadap populasi atau sampel tertentu dengan tujuan untuk menguji hipotesis yang telah ditetapkan (Sugiyono:2016).

\section{Populasi dan Sampel}

Populasi dalam penelitian ini adalah seluruh KSP dan KSPPS yang terdaftar di Kota Bogor. Sedangkan, sampel dilakukan secara purposive sampling dengan tujuan untuk mendapatkan sampel yang representatif sesuai dengan kriteria yang ditentukan. Adapun kriteria yang ditetapkan dalam pengambilan sampel penelitian ini adalah: Koperasi yang dinyatakan aktif; Jenis usaha adalah simpan pinjam; Mempunyai modal pinjaman; Koperasi melakukan RAT; Beranggotakan minimal 50 orang; Memiliki data keuangan representatif selama periode 2013-2017. 
Tabel 2. Daftar Sampel KSP dan KSPPS Aktif di Kota Bogor.

\begin{tabular}{cll}
\hline NO. & \multicolumn{1}{c}{ NAMA KSP } & \multicolumn{1}{c}{ ALAMAT } \\
\hline 1. & KSP Sumber Rezeki & Jl. Cimanggu No. 52 RT.1/RW.2 Kedung Badak, Kec.Tanah Sareal \\
2. & KSP Wira Karya & Jl. Warung Jambu, Kel. Kedung Badak, Kec. Tanah Sareal \\
3. & KSP Sepakat Satu & Jl. Cermai No. 47, Kel. Bantarjati, Kec. Bogor Utara \\
4. & KSP Mitra Kencana Utama & Jl. Tentram No.14, Kel. Kedung Halang, Kec. Bogor Utara \\
5. & KSPPS BMT Binaul Ummah & Jl. Sumata Dereja No 10 Kel. Pamoyanan \\
6. & KBMT Wihdatul Ummah & Jl. Gunung Batu No. 61A, Kel. Gn. Batu, Kec. Bogor Utara \\
\hline & Sumber :Kantor Koperasi dan UMKM Kota Bogor, 2019.
\end{tabular}

\section{Variabel Penelitian}

Variabel yang digunakan dalam penelitian ini adalah variabel dependen (variabel terikat) dan independen (variabel bebas). Menurut Sugiyono (2016) dapat dijelasankan sebagai berikut.

\section{Variabel Dependen (Y)}

Variabel dependen adalah variabel yang dipengaruhi atau yang menjadi akibat, karena adanya variabel bebas. Dalam penelitian, variabel dependen yang akan diteliti adalah SHU (Y).

\section{Variabel independen (X)}

Variabel independen merupakan variabel yang mempengaruhi atau yang menjadi sebab perubahannya atau timbulnya variabel dependen (terikat). Pada penelitian ini yang menjadi variabel independen, di antaranya adalah jumlah anggota $\left(\mathrm{X}_{1}\right)$, total aset $\left(\mathrm{X}_{2}\right)$, modal sendiri $\left(\mathrm{X}_{3}\right)$, dan modal pinjaman $\left(\mathrm{X}_{4}\right)$.

\section{Definisi Operasionalisasi Variabel}

Rincian operasionaisasi variabel dari penelitian ini dapat dilihat pada Tabel 3.2 berikut ini.

\section{Tabel 3. Operasionalisasi Variabel}

\begin{tabular}{|c|c|c|c|}
\hline & Konsep Variabel & Indikator & Skala Ukur \\
\hline $\begin{array}{l}\text { Jumlah } \\
\text { Anggota }\left(X_{1}\right)\end{array}$ & $\begin{array}{l}\text { Anggota Koperasi adalah pemilik dan } \\
\text { sekaligus pengguna jasa koperasi. (UU No. } \\
25 \text { Tahun 1992) }\end{array}$ & $\begin{array}{l}\text { 1. Pemilik } \\
\text { 2. Pengguna }\end{array}$ & Rasio \\
\hline $\begin{array}{l}\text { Total Aset } \\
\left(\mathrm{X}_{2}\right)\end{array}$ & $\begin{array}{l}\text { Aset adalah kekayaan yang dimiliki dan } \\
\text { dikelola koperasi untuk menjalankan } \\
\text { operasional usaha dalam bentuk harta } \\
\text { lancar dan atau harta tetap. (Permen } \\
\text { Menteri Koperasi dan Usaha Kecil dan } \\
\text { Menengah RI No. Nukm/Ix/2015 tentang Usaha } \\
\text { 15/Per/M.Kukm } \\
\text { Simpan Pinjam oleh Koperasi) }\end{array}$ & $\begin{array}{l}\text { 1. Harta Lancar } \\
\text { 2. Harta Tetap }\end{array}$ & Rasio \\
\hline $\begin{array}{l}\text { Modal Sendiri } \\
\left(\mathrm{X}_{3}\right)\end{array}$ & $\begin{array}{l}\text { modal sendiri adalah modal yang berasal } \\
\text { dari perusahaan itu sendiri (cadangan, } \\
\text { laba) atau berasal dari pengambil bagian, } \\
\text { peserta atau pemilik (modal saham, } \\
\text { modal peserta, dll).(Riyanto,2001: } 21 \text { ) }\end{array}$ & $\begin{array}{l}\text { 1. Simpanan pokok } \\
\text { 2. Simpanan wajib } \\
\text { 3. Dana cadangan } \\
\text { 4. Donasi dan } \\
\text { hibah }\end{array}$ & Rasio \\
\hline $\begin{array}{l}\text { Modal } \\
\text { Pinjaman }\left(\mathrm{X}_{4}\right)\end{array}$ & $\begin{array}{l}\text { Modal yang berasal dari para anggota } \\
\text { sendiri atau dari koperasi lain atau dari } \\
\text { lembaga-lembaga keuangan/bank. (UU } \\
\text { No. } 25 \quad \text { Tahun } 1992 \text { tentang } \\
\text { Perkoperasian) }\end{array}$ & $\begin{array}{l}\text { 1. Anggota } \\
\text { 2. Koperasi lainnya } \\
\text { dan/atau } \\
\text { anggotanya } \\
\text { 3. Bank dan lembaga } \\
\text { keuangan lainnya } \\
\text { 4. Penerbitan } \\
\text { obligasi dan surat } \\
\text { hutang lainnya }\end{array}$ & Rasio \\
\hline
\end{tabular}




\begin{tabular}{lllll}
\hline Sisa Hasil & Merupakan pendapatan koperasi yang & 1. & Total & Rasio \\
Usaha (Y) & diperoleh dalam satu tahun buku & penerimaan & \\
& dikurangi dengan biaya penyusutan, dan & 2. & Total biaya dan \\
& kewajiban lainnya termasuk pajak dalam & & \\
& beban & \\
& 25 Tahun buku yang bersangkutan. (UU No. & & \\
& & & \\
\hline
\end{tabular}

\section{Metode Analisis Data}

Analisis data merupakan metode yang menggambarkan sejauh mana suatu variabel memiliki hubungan/pengaruh terhadap variabel lain.

\section{Uji Asumsi Klasik}

Sebelum metode regresi linier berganda digunakan dalam pengujian hipotesis, terlebih dahulu model tersebut akan diuji apakah metode tersebut memenuhi asumsi klasik atau tidak model yang diperoleh benar-benar memenuhi asumsi dasar dalam analisis regresi.

\section{Uji Normalitas}

Menurut Gunawan (2016:93) semua uji statistik haruslah melakukan uji distribusi normal. Uji normalitas data dapat dilakukan dengan metode grafik histogram, normal probability plot serta uji Kolmogorov Smirnov.

\section{Tabel 5. Hasil uji Kolmogorov- Smirnov}

One-Sample Kolmogorov-Smirnov Test

\begin{tabular}{llr}
\hline & & \\
\hline $\mathrm{N}$ & & Unstandardized Residual \\
Normal Parameters & \\
& Mean & 30 \\
& Std. Deviation &, 0000000 \\
Most Extreme & Absolute & 27731688,3320 \\
Differences & Positive &, 270 \\
& Negative &, 270 \\
Test Statistic & &,- 234 \\
Asymp. Sig. (2-tailed) & &, 256 \\
\hline
\end{tabular}

Berdasarkan hasil analisis uji Kolmogorov-Smirnov pada Tabel 3 diketahui bahwa data berdistribusi normal karena nilai Asymp. Sig. Sebesar 0,118>0,05.

\section{Uji Multikolinearitas}

Menurut Ghozali (2011:105), uji multikolinearitas bertujuan untuk menguji apakah model regresi ditemukan adanya korelasi antar variabel bebas (independen).
Untuk mengetahui ada tidaknya multikolinieritas dalam model regresi pada penelitian ini menggunakan besaran tolerance dan Variance Inflantion Factor (VIF), di mana dikatakan bahwa tidak terjadi multikolinearitas apabila nilai tolerance > 0.05 atau VIF < 5. Model regresi linier harus terbebas dari gejala multikolinearitas agar dapat digunakan dalam penelitian.

\section{Tabel 6. Hasil Uji Multikolinearitas}

\begin{tabular}{lccc}
\hline \multirow{2}{*}{ Model } & \multicolumn{3}{c}{ Collinearity Statistic } \\
\cline { 2 - 4 } & Tolerance & VIF & Keputusan \\
\hline Jumlah Anggota $\left(\mathrm{X}_{1}\right)$ &, 465 & 2,150 & Bebas multikolinearitas \\
Total aset $\left(\mathrm{X}_{2}\right)$ &, 129 & 4,755 & Bebas multikolinearitas \\
Modal Sendiri $\left(\mathrm{X}_{3}\right)$ &, 443 & 2,260 & Bebas multikolinearitas \\
Modal pinjaman $\left(\mathrm{X}_{4}\right)$ &, 164 & 3,088 & Bebas multikolinearitas \\
\hline
\end{tabular}




\section{Uji Autokorelasi}

Uji autokorelasi bertujuan menguji apakah dalam model regresi ada korelasi antara kesalahan pengganggu pada periode $t$ dengan kesalahan pengganggu pada periode t-1 atau sebelumnya (Ghozali, 2011:110).
Penelitian ini menggunakan uji DurbinWatson, dengan ketentuan jika nilai DurbinWatson sama dengan $1<\mathrm{DW}>3$, maka terjadi autokorelasi. Jika $1<\mathrm{DW}<3$, maka tidak terjadi autokorelasi (Sarwono, 2012:66).

Tabel 7. Hasil Uji Durbin watson

\begin{tabular}{|c|c|c|c|c|c|}
\hline \multicolumn{6}{|c|}{ Model Summary $^{\mathbf{b}}$} \\
\hline Model & $\mathrm{R}$ & $\begin{array}{c}\mathrm{R} \\
\text { Square }\end{array}$ & $\begin{array}{l}\text { Adjusted R } \\
\text { Square }\end{array}$ & $\begin{array}{l}\text { Std. Error of the } \\
\text { Estimate }\end{array}$ & Durbin Watson \\
\hline 1 &, $733^{a}$ &, 537 & ,463 & 29867942,410 & 1,419 \\
\hline
\end{tabular}

Predictors: (Constant), Jumlah Anggota, Total Aset, Modal Sendiri, Modal pinjamanDependent Variable: Sisa Hasil Usaha. Sumber: Data Sekunder (Diolah), 2018. Dari Tabel 4 dapat disimpulkan bahwa tidak ada autokorelasi antara variabel yang diteliti karena nilai Durbin-Watson sebesar 2,521 di mana $1<2,521<3$.

\section{Uji Heteroskedastisitas}

Menurut Ghozali (2011:139), uji heteroskedastisitas bertujuan untuk menguji apakah model regresi terjadi ketidaksamaan varians dari residual satu pengamatan ke pengamatan lain. Penelitian ini menggunakan uji scatter plot.

Berdasarkan Gambar 3. diketahui bahwa pencaran data tidak menunjukkan pola tertentu dan menyebar secara acak, baik di atas maupun di bawah angka nol pada sumbu Y. Oleh karena itu, dapat disimpulkan bahwa tidak ada gejala heteroskedastisitas pada penelitian ini.

\section{Analisis Regresi Berganda}

Untuk menguji hipotesis penelitian, digunakan regresi berganda untuk mengetahui pengaruh variabel bebas terhadap variabel terikat adalah sebagai berikut.

Menentukan model berdasarkan paradigma penelitian. Prosedur analisis data diawali dengan menentukan paradigma penelitian berdasarkan kerangka pemikiran.

\section{Persamaan strukturalnya}

Untuk mengukur pengaruh antara suatu variabel dependent dengan dua atau lebih variabel independent persamaan:

$$
\mathrm{Y}=\mathrm{a}+\beta_{1} \mathrm{X}_{1}+\beta_{2} \mathrm{X}_{2}+\beta_{3} \mathrm{X}_{3}+\beta_{4} \mathrm{X}_{4}+\varepsilon
$$

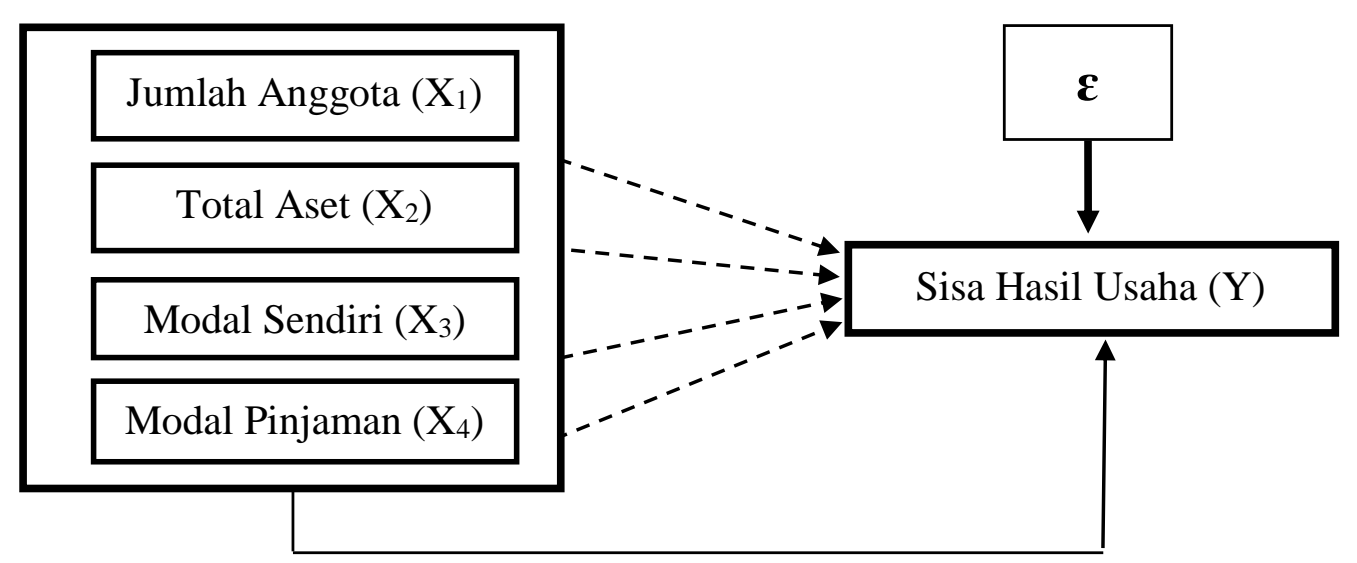

Gambar 3. Hubungan antara Variabel Penelitian 
Analisis Korelasi Berganda

Untuk mengetahui bagaimana hubungan antar modal sendiri, modal pinjaman, dan volume usaha terhadap sisa hasil usaha (SHU) maka digunakan rumus sebagai berikut ( Sugiyono, 2000).

$$
r X i Y=\frac{n \Sigma X i Y-(\Sigma X i)(\Sigma Y)}{\sqrt{\left\{n \Sigma X i^{2}-\left(\Sigma X i^{2}\right)\right\}\left\{n \Sigma Y^{2}-(\Sigma Y)\right\}}}
$$

Dari rumus analisis korelasi diatas, maka akan di peroleh nilai $r$ yang besarnya antara $-1,0$ sampai 1 . Ketentuan nilai r yaitu:

\section{Tabel 8. Interpretasi terhadap Nilai $r$} Hasil Analisis Korelasi.

\begin{tabular}{cl}
\hline Interval Nilai $r$ & Interpretasi \\
\hline $0,001-0,200$ & Sangat Lemah \\
$0,201-0,400$ & Lemah \\
$0,401-0,600$ & Cukup Kuat \\
$0,601-0,800$ & Kuat \\
$0,801-1,000$ & Sangat Kuat \\
\hline \multicolumn{2}{c}{ HASIL DAN PEMBAHASAN }
\end{tabular}

Berdasarkan hasil yang tercantum pada Tabel 1, diketahui bahwa secara umum KSP di Kota Bogor mengalami perkembangan jumlah anggota yang meningkat dengan persentase sebesar 7,31\%. Kondisi tersebut merupakan hal yang baik bagi KSP karena dengan meningkatnya jumlah anggota berarti akan meningkatkan kegiatan koperasi sehingga keaktifan anggota dalam bertransaksi dan pembiayaan koperasi akan meningkatkan modal koperasi yang meningkatkan SHU. Selain jumlah anggota yang mengalami perubahan, total aset juga mengalami perubahan yang mengindikasikan adanya perubahan pada struktur keuangan KSP di Kota Bogor.

Nilai rata-rata total aset mengalami perkembangan sebesar 2,97\%. Hal ini berarti bahwa KSP memiliki kemampuan untuk mengefesiensikan biaya dan mengoperasikan aset yang dimiliki tersebut sehingga dapat diserap oleh anggotanya. Peningkatan total aset mengindikasikan bahwa kekayaan KSP bertambah dan SHU meningkat, serta kesejahteraan anggota ikut meningkat. Selain jumlah anggota dan total aset, faktor lain yang dapat mempengaruhi sisa hasil usaha KSP adalah modal sendiri.

Perubahan modal sendiri mengalami peningkatan rata-rata sebesar $0,82 \%$. Hal ini menunjukan bahwa kemampuan koperasi dalam mencari modal dari sumber internal koperasi cukup baik. Sebaliknya, hanya sebuah koperasi yang mengalami penurunan modal sendiri, yaitu KSP Sumber Rezeki dengan persentase penurunan sebesar $2,67 \%$. Perubahan modal sendiri yang menurun atau meningkat tersebut mengindikasikan adanya perubahan pada struktur modal KSP. Selain modal sendiri koperasi juga menggunakan modal pinjaman dalam struktur modal KSP di Kota Bogor.

Perubahan modal pinjaman mengalami peningkatan rata-rata sebesar $8,48 \%$. Kondisi tersebut merupakan hal yang baik bagi KSP karena dengan meningkatnya modal pinjaman berarti ketergantungan KSP terhadap pihak lain meningkat. Sebaliknya, sebanyak 2 (dua) koperasi mengalami penurunan modal pinjaman.

Pengaruh Secara Simultan dan Parsial Jumlah Anggota, Total Aset, Modal Sendiri, dan Modal Pinjaman terhadap Sisa Hasil Usaha pada KSP di Kota Bogor. Analisis regresi berganda digunakan untuk mengetahui seberapa besar pengaruh variabel-variabel bebas (independent) yaitu jumlah anggota $\left(\mathrm{X}_{1}\right)$, total aset $\left(\mathrm{X}_{2}\right)$, modal sendiri $\left(\mathrm{X}_{3}\right)$ dan modal pinjaman $\left(\mathrm{X}_{4}\right)$ terhadap variabel terikat (dependent) yaitu sisa hasil usaha (Y). Hasil analisis regresi linier berganda dapat dilihat sebagai berikut: 
Tabel 10. Hasil Regresi Berganda Coefficients $^{\mathrm{a}}$

\begin{tabular}{lrrrrr}
\hline \multirow{2}{*}{ Model } & Unstandardized Coefficients & $\begin{array}{c}\text { Standardized } \\
\text { Coefficients }\end{array}$ & t & \multirow{2}{*}{ Sig. } \\
\cline { 2 - 5 } & \multicolumn{1}{c}{ B } & Std. Error & Beta & & \\
\hline \multirow{2}{*}{ (Constant) } & $-3,649$ & 2,653 & & -459 &, 650 \\
\cline { 2 - 5 } 1 &, 089 & 0,055 &, 323 & 1,721 &, 019 \\
Jumlah anggota &, 012 &, 004 & 1,264 & 3.337 &, 003 \\
Total Aset &, 150 &, 057 &, 538 & 2,632 &, 014 \\
Modal Sendiri &,- 015 &, 004 & $-1,116$ & $-3,325$ &, 003 \\
\hline
\end{tabular}

Berdasarkan Tabel tersebut maka diperoleh suatu model regresi:

$$
\begin{aligned}
& \mathrm{Y}=-2,649+0,089 \mathrm{X}_{1}+0,12 \mathrm{X}_{2}+0,15 \\
& \mathrm{X}_{3}-0,015 \mathrm{X}_{4}+\varepsilon \\
& \text { Hasil tersebut diinterpretasikan: Nilai }
\end{aligned}
$$
konstanta sebesar $-3,649$ dan bertanda negatif menyatakan bahwa apabila nilai jumlah anggota, total aset, modal sendiri, dan modal pinjaman dianggap nol, maka sisa hasil usaha sebesar Rp -2,649.000,-.

Koefisien regresi jumlah anggota $\left(\mathrm{X}_{1}\right)$ sebesar 0,089 dan bertanda positif menyatakan bahwa apabila terjadi peningkatan jumlah anggota sebesar 10\%, maka akan meningkatkan jumlah sisa hasil usaha sebesar Rp890.000,- dan sebaliknya.

Koefisien regresi total aset $\left(\mathrm{X}_{2}\right)$ sebesar 0,12 dan bertanda positif menyatakan bahwa apabila terjadi peningkatan total aset sebesar Rp1.000.000, maka akan meningkatkan jumlah sisa hasil usaha sebesar Rp120.000 dan sebaliknya.

Koefisien regresi modal sendiri $\left(\mathrm{X}_{3}\right)$ sebesar 0,15 dan bertanda positif menyatakan bahwa apabila terjadi peningkatan modal sendiri sebesar Rp1.000.000, maka akan meningkatkan jumlah sisa hasil usaha sebesar Rp150.000 dan sebaliknya.

Koefisien regresi modal pinjaman $\left(\mathrm{X}_{4}\right)$ sebesar $-0,015$ dan bertanda negatif menyatakan bahwa apabila terjadi peningkatan modal pinjaman sebesar Rp1.000.000, maka akan menurunkan jumlah sisa hasil usaha sebesar Rp15.000 dan sebaliknya.

\section{Analisis Korelasi Berganda}

Analisis korelasi berganda digunakan untuk melihat seberapa besar hubungan yang terjadi antara variabel independen yaitu modal sendiri $\left(\mathrm{X}_{1}\right)$, total aset $\left(\mathrm{X}_{2}\right)$, modal sendiri $\left(\mathrm{X}_{3}\right)$, dan modal pinjaman $\left(\mathrm{X}_{4}\right)$ terhadap variabel dependen, yaitu sisa hasil usaha (Y). Nilai koefisien korelasi berkisar antara 0 sampai dengan 1 , nilai yang semakin mendekati 1 mengindikasikan adanya hubungan yang kuat dan searah. Berikut ini adalah hasil analisis korelasi berganda.

Tabel 11. Hasil Analisis Korelasi Berganda

\begin{tabular}{lccccc}
\hline \multicolumn{5}{c}{ Model Summary } \\
\hline Model & R & R Square & $\begin{array}{c}\text { Adjusted R } \\
\text { Square }\end{array}$ & $\begin{array}{l}\text { Std. Error of } \\
\text { the Estimate }\end{array}$ & Durbin-Watson \\
\hline 1 &, $733^{\mathrm{a}}$ &, 537 & \multicolumn{4}{c}{, 463} & 29867942,410 & 1,419 \\
\hline $\begin{array}{l}\text { Predictors: (Constant): Jumlah Anggota, Total Aset, Modal Sendiri, Modal Pinjaman } \\
\text { Dependent Variable: Sisa Hasil Usaha }\end{array}$ & & &
\end{tabular}

Berdasarkan hasil analisis korelasi berganda pada Tabel 4.4 diperoleh nilai $\mathrm{R}$ sebesar 0,733 nilai tersebut berada pada kategori kuat $(0,601-0,800)$ dan positif, menunjukkan bahwa derajat kekuatan antara variabel jumlah anggota, total aset, modal sendiri, dan modal pinjaman berada pada derajat hubungan yang kuat terhadap sisa hasil usaha. Artinya, apabila nilai jumlah anggota, total aset, modal sendiri, dan modal pinjaman semakin tinggi, maka SHU semakin meningkat dan sebaliknya. 


\section{Koefisien Determinasi $\left(\mathbf{R}^{\mathbf{2}}\right)$}

Berdasarkan Tabel, diketahui bahwa hasil yang diperoleh dari R square sebesar 0,537 atau $53,7 \%$. Hal ini menunjukkan bahwa persentase sumbangan pengaruh variabel nilai jumlah anggota, total aset, modal sendiri, dan modal pinjaman terhadap sisa hasil usaha sebesar 52,7\%. Sebaliknya, sisanya $46,3 \%$ dipengaruhi oleh variabel lain yang tidak dimasukkan dalam model penelitian ini seperti partisipasi anggota, volume usaha, tingkat suku bunga, likuiditas, solvabilitas. (Keputusan Menteri Koperasi dan UMKM No.29 tahun 2002)

\section{Pengujian Hipotesis}

\section{Uji F}

Pengujian menggunakan uji $\mathrm{F}$ dengan tingkat probabilitas standar $0,05(\alpha=5 \%)$. Adapun kriteria pengambilan keputusan Uji $\mathrm{F}$ adalah: Ho: $\beta \mathrm{i} \leq 0$ : jumlah anggota, total aset, modal sendiri, dan modal pinjaman secara simultan tidak berpengaruh positif dan signifikan terhadap SHU pada KSP di Kota Bogor.

Ha: $\beta \mathrm{i}>0$ : jumlah anggota, total aset, modal sendiri, dan modal pinjaman secara simultan berpengaruh positif dan signifikan terhadap SHU pada KSP di Kota Bogor.

Tabel 12 Hasil Uji F

ANOVA $^{\mathrm{a}}$

\begin{tabular}{ccccccc}
\hline & Model & Sum of Squares & Df & Mean Square & F & Sig. \\
\hline \multirow{2}{*}{1} & Regression & 25,868 & 4 & 64,669 & 7,249 &, $001^{\mathrm{b}}$ \\
& Residual & 22,302 & 25 & 89,209 & & \\
& Total & 48,170 & 29 & & & \\
\hline
\end{tabular}

Dependent Variable: Sisa Hasil Usaha

Predictors: (Constant), Jumlah Anggota, Total Aset, Modal Sendiri, Modal Pinjaman

Hasil uji F pada Tabel 4.5 diketahui bahwa

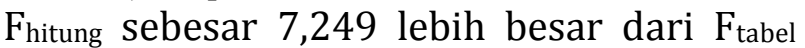
dengan $\mathrm{df}_{1}=\mathrm{k}-1$ atau 4-1= 3 dan $\mathrm{df}_{2}=\mathrm{n}-\mathrm{k}$ atau $30-4=26$ serta taraf $\alpha=0,05$ sebesar 2,99. Sehingga $F_{\text {hitung }}$ lebih besar dari $F_{\text {tabel }}$ $(7,249>2,99)$, serta nilai probabilitas yang lebih kecil dari nilai probabilitas standar $(0,01<0,05)$, maka Ho ditolak dan $\mathrm{Ha}$ diterima. Dapat disimpulkan bahwa jumlah anggota $\left(\mathrm{X}_{1}\right)$, total aset $\left(\mathrm{X}_{2}\right)$, modal pinjaman $\left(\mathrm{X}_{2}\right)$, dan modal pinjaman $\left(\mathrm{X}_{3}\right)$ secara simultan berpengaruh positif dan signifikan terhadap sisa hasil usaha (Y) KSP di Kota Bogor.

Uji t

Untuk mngetahui pengaruh jumlah anggota $\left(X_{1}\right)$, total aset $\left(X_{2}\right)$, modal sendiri $\left(X_{3}\right)$, dan modal pinjaman $\left(\mathrm{X}_{4}\right)$ secara parsial terhadap variabel sisa hasil usaha (Y), maka dilakukan pengujian hipotesis menggunakan uji $t$ dengan nilai probabilitas standar $0,05(\alpha=$ $5 \%)$ dan derajat kebebasan sebesar n-k (30$4)=26$. Hasil rekapitulasi uji t dapat dilihat pada Tabel 4.6 berikut ini

Tabel 13. Rekapitulasi Pengujian secara parsial.

\begin{tabular}{clccl}
\hline No & \multicolumn{1}{c}{ Variabel } & $\mathbf{t}_{\text {hitung }}$ & t tabel & \multicolumn{1}{c}{ Kesimpulan } \\
\hline 1 & Jumlah Anggota $\left(\mathrm{X}_{1}\right)$ & 1,721 & 1,706 & Berpengaruh positif dan signifikan \\
2 & Total Aset $\left(\mathrm{X}_{2}\right)$ & 3,337 & 1,706 & Berpengaruh positif dan signifikan \\
3 & Modal Sendiri $\left(\mathrm{X}_{3}\right)$ & 2,632 & 1,706 & Berpengaruh positif dan signifikan \\
4 & Modal Pinjaman $\left(\mathrm{X}_{4}\right)$ & $-3,325$ & 1,706 & Tidak Berpengaruh positif dan signifikan \\
\hline
\end{tabular}

Hasil rekapitulasi di atas menunjukkan bahwa variabel jumlah anggota, total aset, dan modal sendiri menjadi faktor yang berpengaruh terhadap SHU pada KSP di Kota Bogor. Hal ini disebabkan karena jumlah anggota, total aset, dan modal sendiri memiliki nilai thitung yang lebih tinggi dan melebihi nilai ttabel dan didukung dengan nilai probabilitas lebih kecil dari nilai probabilitas standar. Semakin kecil nilai probabilitas yang didapat maka akan semakin signifikan pengaruhnya terhadap SHU. Sebaliknya, variabel modal pinjaman tidak berpengaruh terhadap SHU pada KSP di Kota Bogor. 


\section{Kesimpulan}

Perkembangan jumlah anggota, total aset, modal sendiri, modal pinjaman, dan SHU pada KSP di Kota Bogor secara umum mengalami kenaikan. Kenaikan tertinggi terjadi pada modal pinjaman. Kemudian, diikuti dengan kenaikan jumlah anggota, total aset, dan SHU. Sebaliknya, kenaikan yang terendah terjadi pada modal sendiri.

Hasil pengujian secara simultan (Uji F) bahwa jumlah anggota, total aset, modal sendiri, dan modal pinjaman secara simultan berpengaruh positif dan signifikan terhadap SHU pada KSP di Kota Bogor.

Hasil pengujian secara parsial (Uji t): Jumlah anggota $\left(\mathrm{X}_{1}\right)$ berpengaruh positif dan signifikan terhadap SHU (Y) pada KSP di Kota Bogor. Total aset $\left(\mathrm{X}_{2}\right)$ berpengaruh positif dan signifikan terhadap SHU (Y) pada KSP di Kota Bogor. Modal sendiri $\left(\mathrm{X}_{3}\right)$ berpengaruh positif dan signifikan terhadap SHU (Y) pada KSP di Kota Bogor. Modal pinjaman ( $\left.\mathrm{X}_{4}\right)$ tidak berpengaruh positif dan signifikan terhadap SHU (Y) pada KSP di Kota Bogor.

\section{Saran}

Hasil penelitian menunjukkan bahwa jumlah anggota merupakan variabel yang paling dominan berpangaruh positif dan signifikan terhadap SHU, maka sebaiknya KSP di Kota Bogor melakukan pendekatan terhadap pengembangan anggota sehingga partisipasi dan keaktifannya lebih meningkat dalam kegiatan simpan pinjam maupun pembiayaan koperasi, karena penambahan jumlah anggota tanpa diikuti partisipasi dan SHU.

Hasil penelitian menunjukkan bahwa modal sendiri merupakan variabel yang relatif besar berpengaruh terhadap SHU, maka sebaiknya KSP di Kota Bogor mempertahankan kondisi struktur modal sendiri, dan berusaha melakukan pengembangan terhadap anggotanya agar anggota menaikkan besarnya simpanan pokok dan simpanan wajib, sehingga dapat meningkatkan modal sendiri.

Hasil penelitian menunjukkan bahwa total aset merupakan variabel yang relatif kecil berpengaruh positif dan signifikan terhadap SHU, maka sebaiknya KSP di Kota Bogor mempertahankan komposisi struktur aset secara efetif karena pertumbuhan total aset merupakan faktor yang ikut mendukung pertumbuhan SHU.

Hasil penelitian menunjukkan bahwa modal pinjaman tidak berpengaruh positif dan signifikan terhadap SHU, maka sebaiknya KSP di Kota Bogor menetapkan besarnya modal pinjaman agar tidak melebihi besarnya modal sendiri. Penambahan modal pinjaman hanya dibenarkan jika penambahan tersebut menguntungkan terhadap SHU. Penambahan modal pinjaman hanya akan menguntungkan terhadap perolehan SHU apabila "rate of return" dari tambahan modal (modal pinjaman tersebut lebih besar dari pada biaya modal atau bunganya.

Bagi peneliti selanjutnya disarankan agar memperluas ukuran sampel dan menambahkan variabel-variabel lain yang tidak diteliti seperti: partisipasi anggota, volume usaha, tingkat suku bunga, likuiditas, solvabilitas, dan lain-lain.

\section{DAFTAR PUSTAKA}

Gunawan, Imam. 2016. Pengantar Statistika Inferensial. Rajawali Pers. Jakarta

Ghozali, Imam. 2009. Ekonometrika: Teori, Konsep dan Aplikasi dengan SPSS 17. Badan Penerbit Universitas Diponegoro. Semarang.

Keown, Arthur J. 2004. Manajemen Keuangan: Prinsip-prinsip Keuangan dan Aplikasi. Alih Bahasa, Haryandini. PT. INDEKS Kelompok GRAMEDIA. Jakarta.

Keputusan Menteri Negara Koperasi dan Usaha Kecil Menegah Nomor: 129/KEP/M.KUKM/XI/2002, Tanggal 29 November 2002 tentang Pedoman Klasifikasi Koperasi.

Keputusan Menteri Koperasi dan UMKM Nomor 29 Tahun 2002.

Meagher, P., Campos, P., Christen, R.P., Druschel, K.,Gallardo, J., Martowijoyo, J. 2006. Microfinance Regulatory in Seven Countries: A Comparative Study. 
Submitted to Sa-Dhan, New Delhi bye The IRIS Center, University of Maryland. Priyatno, Duwi, 2011. Buku Saku Analisis Statistik Data SPSS. Mediakom. Yogyakarta.

Permen Menteri Koperasi dan Usaha Kecil dan Menengah RI No. 15/Per/M.Kukm/Ix/2015 tentang Usaha Simpan Pinjam oleh Koperasi.

Riyanto, Bambang. 2008. Dasar-dasar Pembelanjaan Perusahaan (Edisi 4). BPFE-UGM. Yogyakarta.
Sugiyono, 2016, Metode Penelitian Kombinasi (Mixed Methods), Cetakan Ketiga, Alfabeta, Bandung. 2000, Metode Penelitian Bisnis, Alfabeta, Bandung.

Tambunan, 2009. Kenapa Koperasi di Negara-Negara Kapitalis/Semi Kapitalis Lebih Maju. www.google.com, Des 2013.

Undang-Undang Republik Indonesia No. 25 tahun 1992 tentang Perkoperasian. 